\title{
PENGARUH MULTINATIONALITY DAN TIMELINESS OF FINANCIAL REPORTING TERHADAP PENGHINDARAN PAJAK
}

(Studi Empiris pada Perusahaan Manufaktur yang terdaftar pada Bursa Efek Indonesia Tahun 2012 hingga Tahun 2016)

\section{MUHAMMAD RIDWAN}

Prodi Akuntansi S1 Universitas Pamulang

*Email: ridwanjack19@gmail.com

\begin{abstract}
Tax Avoidance is a step taken by many taxpayers because it doesn't violate the law, supporting factors can be in the form of Multinationality and Timeliness of Financial Reporting. This research was conducted on companies listed on the Indonesia Stock Exchange during the observation period of 2012-2016. The sampling method used was purposive sampling method with a sample of 32 consisting of 8 manufacturing companies over a period of 4 consecutive years of observation. Based on the result of multiple linear analys regression, the result of the study show that the Multinationality variable has no effect on the effective tax rate, while the timeliness of financial reporting has a negative effect on the effective tax rate.
\end{abstract}

Keywords: Multinationality, Timesliness of Financial reporting and Tax Avoidance

\section{PENDAHULUAN}

\section{Latar Belakang}

Ekonomi Indonesia sekarang ini berkembang jauh lebih baik, hal tersebut didorong dengan kemajuan teknologi sehingga menumbuhkan perusahaanperusahaan multinational yang lingkup operasionalnya tidak hanya dalam negeri melainkan merambah ke luar negeri atau mancanegara. Permasalahan yang sering dihadapi perusahaan yang berskala multinasional adalah adanya tarif pajak yang berbeda diantara negara sehingga seringkali perusahaan-perusahaan multinasional melakukan cara dan metode dalam melakukan Tax Avoidance atau penghindaran pajak.

Seperti juga yang terjadi pada negara Indonesia, bahwa Indonesia tidaklah luput dari praktik tax avoidance atau penghindaran pajak juga yang sudah dilakukan para wajib pajak yang sudah terdaftar di kesatuan negara ini. Aryobimo 
(2012) mengungkapkan, pajak yang adalah sumber masukan terbesar bagi negara yang dananya digunakan sebagai pembiayaan pengeluaran serta kebutuhan pemerintah dan pembangunan nasional. Maka inilah yang dijadikan pemerintah untuk menerima sebanyak mungkin pemasukan dari sektor pajak ini, begitu juga sebaiknya bagi wajib pajak hal ini merupakan biaya yang menjadi tanggungan perusahaan sehingga banyak pengusaha yang berupaya untuk melakukan Tax Avoidance dengan cara-cara yang masih diperbolehkan oleh negara Indonesia.

Kaitan pembayaran pajak yang dilakukan wajib pajak adalah adanya laba diperoleh perusahaan, sehingga sajian laba yang terdapat dalam laporan keuangan suatu perusahaan sangatlah penting sebagai dasar perhitungan pajak yang harus ditunaikan. Ketepatan waktu (timeliness) dalam pelaporan suatu laporan keuangan menjadi begitu penting bagi para pemakai laporan keuangan untuk membuat keputusan dalam rangka memenuhi prinsip keterbukaan sesuai dengan keputusan Bapepam nomor 40/BL/2007.

Tax Avoidance dapat saja mempengaruhi waktu penyampaian laporan keuangan secara berkala. Hal ini dikarenakan proses perumusan Tax Avoidance sampai pada tahap peneyelesaian sangat membutuhkan waktu, sehingga menimbulkan isu yang sangat sensitif. Disisi lain juga Tax Avoidance akan mengurangi biaya dan akan meningkatkan laba perusahaan pada periode tertentu.

Penelitian tentang Multinationality tentang Tax Avoidance yang dapat mempengaruhinya pernah dilakukan oleh Hidayah (2015) menyatakan Tax Avoidance yang dilakukan oleh perusahaan multinasional dengan mendirikan perusahaan bertempat pada negara yang menganut aturan Tax haven yang mampu memberi subsidi pajak berupa pemberian yang rendah terhadap tarif pajak yang dikenakan kepada investor, atau pemodal dengan rahasia yang terjamin.

Atas uraian tersebutlah maka penulis mengambil langkah untuk melakukan penelitian berupa "Pengaruh Multinationality dan Timeliness of Financial Reporting terhadap Tax Avoidance.

\section{Rumusan Masalah}

1. Apakah Multinationality berpengaruh secara signifikan terhadap Tax Avoidance?

2. Apakah Timeliness of Financial Reporting berpengaruh secara signifikan terhadap Tax Avoidance?

3. Apakah Multinationality dan Timeliness of Financial Reporting berpengaruh secara signifikan terhadap Tax Avoidanve?

\section{Tujuan Penelitian}

1. Ingin mengetahui Multinationality berpengaruh secara signifikan terhadap Tax Avoidance.

2. Ingin mengetahui Timeliness of Financial Reporting berpengaruh secara signifikan terhadap Tax Avoidance. 
3. Ingin mengetahui Multinationality dan Timeliness of Finacial Reporting berpengaruh secara signifikan terhadap Tax Avoidance.

\section{TINJAUAN PUSTAKA}

\section{Dasar Teori}

\section{Konsep Dasar Perpajakan}

Pajak juga merupakan suatu kontribusi wajib pajak kepada negara atas badan atau orang pribadi dengan sifat memaksa berdasarkan Undang-Undang dan tidak memperoleh prestasi langsung dan untuk digunakan bagi keperluan negara pada sebesar-besarnya kemakmuran rakyat. (Undang-Undang No. 28 tahun 2007 pasal 1 ayat 1$)$.

\section{Penghindaran Pajak (Tax Avoidance)}

Prastiwi (2015) mengungkapkan penghindaran pajak atau (tax Avoidance) adalah langkah terencana memaksimalkan pendapatan setelah pajak yang dilakukan secara legal dengan tidak melanggar perundang-undangan pajak yang berlaku di negara Indonesia.

\section{Multinationality}

Multinationality merupakan perusahaan kegiatan operasi di berbagai negara dengan tingkat kontrol utama berada pada negara asal dimana usaha tersebut berawal, disamping itu perusahaan multinasional ini juga mempunyai ciri yang berbeda antara negara satu dengan lainnya, yang perbedaan tersebut meliputi ekonomi, budaya, politik dan sosial. Hal ini yang menyebabkan perusahaan multinasional mampu memanfaatkan utang dan penghasilan dalam perencanaan pajak untuk menekan beban pajak dengan cara mengakui beban bunga sebagai biaya fiskal.

Dengan demikian setoran modal dan bunga yang dibayar dari anak perusahaan kepada induk perusahaan berasal dari utang yang dilakukan induk perusahaan. Sehingga induk perusahaan menganggap itu bukan merupakan pendapatan deviden. Perusahaan multinasional melakukan pemaksimalan keuntungan karena perusahaan tersebut memiliki lebih dari satu anak cabang, sehingga dengan pemaksimalan keuntungan ini dapat mengikis segala biaya modal, sebab para pemodal (Luar Negeri) asing mampu menerima tingkat keuntungan yang lebih sedikit dibanding pemodal lokal (domestik).

\section{Timeliness of Financial Reporting (Ketepatan waktu penyampaian laporan} keuangan).

Ketepatan waktu dapat didefinisikan dengan menyampaian laporan keuangan sesegera mungkin yang hal ini dimungkinkan agar tidak menimbulkan keterlambatan dalam pengambilan keputusan.

Chamber dan Penman dalam Alexius Edwin (2012:9) ketepatan waktu diuraikan dalam dua cara yaitu: 
1. Keterlambatan waktu pelaporan dari tanggal pelaporan keuangan sampai tanggal melaporkan.

2. Ditentukan dengan ketepatan waktu pelaporan relatif atas tanggal pelaporan yang diharapkan.

Informasi dari sebuah laporan keuangan merupakan bukti yang memiliki kekuatan yang dapat mempengaruhi keputusan pemodal saham. Informasi ini akan jadi bermanfaat manakala penyampaiannya tepat waktu dimana maksud dari tepat waktu ini disajikan secara relevan dan sesuai dengan kaidah pedoman standar keuangan yang berlaku di negara kita.

\section{Tinjauan Peneliti Terdahulu}

Beberapa peneliti terdahulu yang berkaitan dengan permasalahan penelitian ini antara lain:

1. Penelitian Nurul Hidayah (2015) memiliki hasil penelitian bahwa Perusahaan yang dimiliki Keluarga, Multinationality Company dan Kepemilikan Institusional memiliki pengaruh terhadap Tax Avoidance.

2. Sedangkan penelitian yang dilakukan oleh Ivan Brian dan Dwi Martani (2014) memiliki hasil dari penelitian tersebut bahwa penghindaran pajak berpengaruh positif terhadap Timeliness of Finacial Reporting sedangkan kepemilikan keluarga tidak berpengaruh terhadap timesliness of Financial Reporting.

\section{Kerangka Konseptual}

Penyusunan kerangka konseptual dalam penelitian sangat perlu dilakukan, hal ini karena kerangka konseptual dapat dijadikan sebagai inti penelian secara sistematis. Sehingga dapat memudahkan pemahaman bagi penulis dan pembaca dalam melakukan pengujian secara empiris.

Kerangka Pemikiran (Kerangka konseptual) penulisan ini digambarkan seperti berikut ini:

Variabel X

\begin{tabular}{|c|c|c|}
\hline Multinationality $\left(\mathrm{X}_{1}\right)$ & & \\
\hline Timeliness of Finacial Reporting $\left(\mathrm{X}_{2}\right)$ & & 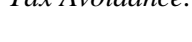 \\
\hline
\end{tabular}

\section{Gambar 1 Kerangka Konseptual}

\section{Pengembangan Hipotesis}

Rumusan masalah dan mencapai tujuan penelitian dapat dijawab dan dijelaskan dengan hipotesis penulisan ini seperti berikut:

$\mathrm{H}_{1} \quad$ : Diduga adanya pengaruh Multinationality terhadap Tax Avoidance. 
$\mathrm{H}_{2} \quad$ : Diduga adanya pengaruh Timeliness of Financial Reporting terhadap Tax Avoidance.

$\mathrm{H}_{3} \quad$ : Diduga adanya penagruh Multinationality dan Timeliness of Financial Reporting terhadap Tax Avoidance.

\section{METODOLOGI PENELITIAN}

\section{Jenis Penelitian}

Penulisan ini peneliti memakai metode kuantitatif yaitu suatu metode dengan cara pendekatan angka-angka dengan teknik pengambilan sampling purposive. Sampling Purposive yaitu penelitian yang mengambil sampel dari populasi berdasarkan kriteria peneliti.

Populasi menurut Umar Kaffi $(1999,107)$ dalam Rr. Dyah Eko Setyowati (2012) adalah keseluruhan objek penelitian merupakan data sumber yang memiliki ciri-ciri tersendiri dalam penelitian dan memiliki tingkat kesempatan sama untuk terpilih menjadi anggota sampel. begitupun sampel merupakan himpunan bagian bagian dari populasi yang menjadi objek yang sebenarnya.

Populasi penelitian ini adalah beberapa perusahaan manufaktur yang terdaftar di Bursa Efek Indonesia (BEI) sebanyak 147 Perusahaan sedangkan sampel yang diambil untuk kasus ini sebanyak 30 data dari 6 perusahaan manufaktur.

\section{Definisi Operasional dan Identifikasi Variabel}

Variabel terikat dan bebas dalam penelitian ini meliputi:

1. Variable Independent (X), yaitu variabel yang memanipulasi dan diduga sebagai penyebab yang mempengaruhi variable dependent $(\mathrm{Y})$, pada penelitian ini variabel bebas $(\mathrm{X})$ adalah:

1) Multinationality (X1)

2) Timeliness of Financial Reporting (X2)

2. Variable Dependent (Y), yaitu Tax Avoidance merupakan variabel terikat yang diproksikan oleh ETR (Effective Tax Rate) yang diperkirakan terjadi sebagai akibat dari interaksi dengan variabel bebas.

\section{Multinationality (X1)}

Multinasional dalam perusahaan merupakan suatu perusahaan dengan operasional kerjanya terdapat diberbagai negara secara besamaan, namun keputusan utama dan paling utama dan alat kontrolnya dilakukan oleh perusahaan pada negara asal. Pengukuran terhadap variabel bebas ini diukur berdasarkan sistem dummy, bila nilai angka 1 bagi perusahaan memiliki minimal 5 (lima) anak perusahaan yang tergabung diluar negara Indonesia, begitupun sebaliknya diberikan angka Nol (0) (Nuraini, 2014).

\section{Timeliness of Financial Reporting (X2)}

Variabel bebas (X) ini yakni Timeliness of Financial Reporting juga menjadi informasi yang relevan serta prasyarat penting agar laporan keuangan 
yang disajikan dapat memenuhi karakteristik kualitatif yaitu relevansi terhadap kebutuhan pihak yang membutuhkan laporan tersebut.

Pengukuran terhadap variabel ini adalah sebagai berikut:

Rentang $\mathrm{n}=$ Tanggal pelaporan $\mathrm{n}-31$ Desember pada $\mathrm{n}$

Keterangan:

Rentang $\mathrm{n} \quad=$ batas waktu untuk laporan keuangan tahun berjalan

Tanggal pelaporan $_{\mathrm{n}}=$ saat penyerahan kepada BAPEPAM (paling lambat akhir bulan Maret tahun selanjutnya)

31 Desember pada $_{\mathrm{n}}=$ saat tutup buku akhir tahun berjalan

\section{Tax Avoidance (Y)}

Variable dependent yang dipakai pada penelitian ini adalah variabel Tax Avoidance (penghindaran pajak), menggunakan ETR (Effective Tax Rate) sebagai proksi dari Tax Avoidance. Effective Tax Rate merupakan Pajak sebagai beban dibagi laba sebelum pajak (including pajak kini dan pajak tangguhan), yang dirumuskan dengan rumus sebagai berikut:

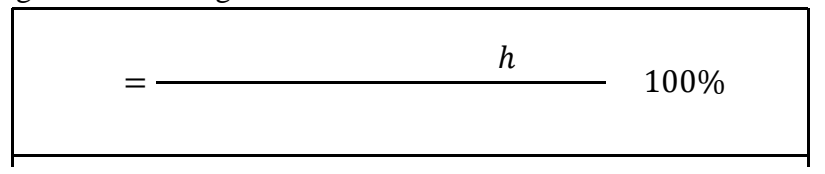

\section{Sumber serta Teknik Pengumpulan Data}

Data sumber penelitian ini menggunakan data sekunder yang didapatkan melalui Website resmi Bursa Effek Indonesia, dengan alat yang digunakan studi kepustakaan dan studi dokumentasi.

\section{Teknis Analisis Data}

Uji Asumsi Klasik

Data yang diolah bisa menjadi sah atau tidaknya suatu model regresi tergantung dari asumsi model penjelas bagi pengaruh antar variabel. Asumsi yang digunakan pada analisis regresi ini adalah sebagai berikut:

\section{Normalitas}

Tujuan dari model regresi ini untuk menguji variabel dependent dan independent mempunyai distribusi normal ataukah tidak. Hasil uji dikatakan baik bila nilai asym. Sig. (2-tailed) memiliki nilai diatas 0,05 .

\section{Heteroskedastisitas}

Tujuan dari model regresi ini untuk menguji ketidaksamaan variance dari residual suatu pengamatan ke pengamatan lainnya. Jika hasilnya tetap maka disebut homoskedastisitas.

\section{Multikolinearitas}

Tujuan dari model regresi ini untuk mengetahui adanya hubungan antar variabel bebas, hasil yang baik adalah tidak adanya korelasi antar variabel bebas tersebut. 


\section{Autokorelasi}

Tujuan dari model regresi ini untuk mengetahui hubungan linier antara kesalahan pengganggu pada periode $t$ dengan kesalahan pengganggu pada periode $\mathrm{t}-1$. Hasil yang baik bila tidak terjadi korelasi antara variabel bebas dan terikat.

\section{Uji Regresi Berganda}

Tujuan regresi ini adalah untuk melihat hubungan dua atau lebih variabel independent terhadap variabel dependent.

Rumus uji regresi linear berganda seperti berikut ini:

$$
\mathbf{Y}=
$$$$
\alpha+\beta 1 X 1+\beta 2 X 2+€
$$

Dimana:

$\mathrm{Y}=$ Variable dependent $($ Effective Tax Rate $)$

$\mathrm{X} 1=$ Variable independent (Multinationality)

$\mathrm{X} 2$ = Variabel independent (Timeliness of Financial Reporting)

$\alpha . \quad=$ Konstanta.

$\beta .=$ Koefisien regresi.

$\varepsilon . \quad=$ Error.

\section{Uji Hipotesis}

Apabila syarat untuk diterimanya suatau model regresi linear dipenuhi semua, maka langkah selanjutnya adalah dilaksanakannya pengujian hipotesis.

1. Uji t

Tujuan uji t ini adalah untuk melihat pengaruh variabel independent secara sendiri-sendiri atau terpisah terhadap variabel dependent. Hipotesis no (H0) akan ditolak apabila diperoleh $\mathrm{t}_{\text {hitung }}$ lebih besar atau sama dengan $\mathrm{t}_{\text {tabel, }}$, atau hasil signifikannya 0,05 , hal ini memiliki arti bahwa antara variable Independent dengan variable dependent terdapat pengaruh.

2. Uji F

Tujuan pengujian ini adalah sebagai alat ukur signifikansi koefisien regresi berganda secara simultan, atau untuk menguji keterandalan model regresi yang dihasilkan. Hipotesis nol (H0) akan ditolak jika diperoleh $\mathrm{F}_{\text {hitung }}$ lebih besar atau sama dengan $\mathrm{F}_{\text {tabel }}$, atau signifikaninya $<0,05$. Ini menunjukkan variabel independent secara simultan mempengaruhi variabel dependent.

\section{HASIL ANALISIS DAN PEMBAHASAN}

Uji Asumsi Klasik

\section{Normalitas}

Tabel 1. Uji Normalitas Data

\begin{tabular}{|l|r|}
\hline & \multicolumn{1}{|c|}{ Unstandardized Res. } \\
\hline Test Value &, 01556 \\
Total Cases & 32 \\
$Z$ & $(1,617)$
\end{tabular}




\begin{tabular}{l|l} 
Asymp Significant (2-tailed) & 0,106 \\
a. Median \\
Sumber: Output IBM SPSS 22,0
\end{tabular}

Berdasarkan hasil SPSS 22.0 di peroleh hasil observasi terlihat bahwa nilai Asymp. significant senilai 0,106 > 0,005 dapat dikatakan bahwa data terdistribusi secara normal.

\section{Heteroskedastisitas}

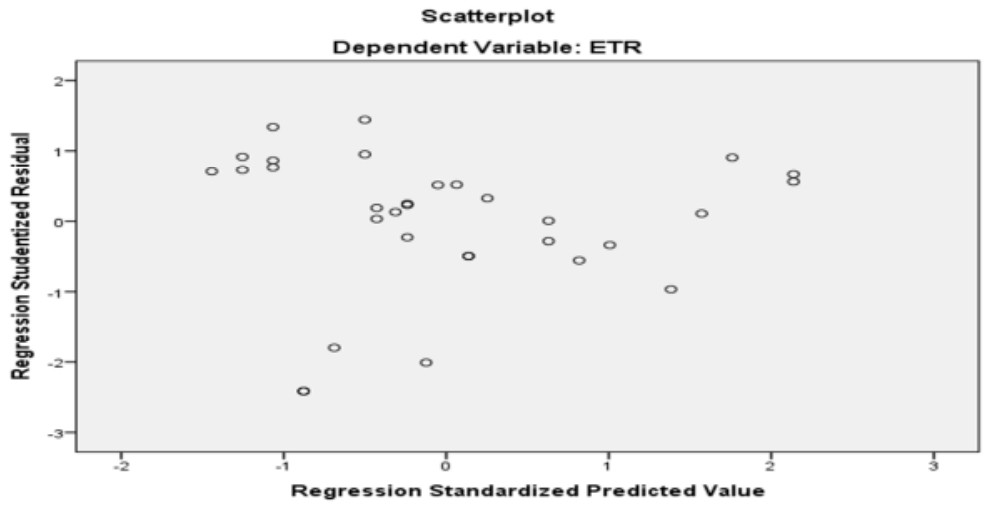

Sumber: Output IBM SPSS 22,0

\section{Gambar 1 Uji Heteroskedastisitas}

Terlihat gambar 1 diatas yaitu grafik scatterplot menunjukan pola noktah yang terdapat pada grafik tersebut menyebar tidak membentuk pola, sehingga dapat ditarik kesimpulan heteroskedastisitas tidak terjadi pada model regresi ini.

\section{Multikolinearitas}

Tabel 2. Uji Multikolinearitas

\begin{tabular}{|ll|r|r|}
\hline \multirow{2}{*}{ Model } & \multicolumn{2}{|c|}{ Collinearity Statistics } \\
\cline { 2 - 3 } \multicolumn{1}{|c|}{ (Constant) } & \multicolumn{1}{|c|}{ Tolerance } \\
\hline 1 & &, 611 & \\
& MULTI &, 611 & 1,637 \\
& TIMESLINESS & & 1,637 \\
\hline
\end{tabular}

Dependent Variable : ETR

Sumber : SPSS 22.0 
Tabel 2 diatas menunjukan hasil tolerance untuk tiap variable independent $>0,10$ sedangkan angka VIF untuk masing-masing variable independent $<10$, sehingga dapat ditarik kesimpulan bahwa regresi dengan model ini tidak terdapat multikolinearitas.

\section{Autokorelasi}

Tabel 3. Uji Autokorelasi

\begin{tabular}{|l|r|}
\hline Model & \multicolumn{2}{|c|}{ Durbin Watson } \\
\hline 1 & \\
\hline
\end{tabular}

Terlihat pada tabel 3 diatas bahwa kolom durbin watson memiliki nilai 1,289 hal ini terbebas dari masalah autokorelasi dikarenakan hasil tersebut berada pada range -2 hingga 2 .

\section{Uji Regresi Berganda}

Tabel 4. Regresi Linier Berganda

\begin{tabular}{|ll|r|r|}
\hline \multirow{2}{*}{ Model } & \multicolumn{3}{|c|}{ Unstandardized Coefficients } \\
\cline { 3 - 4 } & (Constant) & B. & \multicolumn{1}{|c|}{ Standard Error. } \\
\hline 1 & MULTI &, 962 &, 211 \\
& TIMESLINESS &, 079 &, 041 \\
& &,- 009 &, 003 \\
\hline
\end{tabular}

Effective Tax Rate $=0,962+0,709 \times 1-0,009 \times 2+\mathrm{e}$

Pada persamaan model regresi berganda diatas dapat dijelaskan sebagai berikut ini:

1. Nilai konstanta 0,962 menjelaskan variabel multinationality, Timeliness of financial reporting yang merupakan variable independent bernilai tetap atau konstan maka nilai variabel tidak bebasnya yaitu Tax Avoidance akan menjadi sebesar $9,62 \%$.

2. Koefisien regresi multinationality senilai 0,079 menjelaskan setiap kenaikan variabel multinationality Rp1 maka variabel tax avoidance akan naik sebesar 0,079 dengan asumsi jika variabel tidak terikatnya adalah tetap.

3. Koefisien Timeliness of financial reporting sebesar -0,009 menjelaskan bahwa setiap penurunan variabel Timeliness of financial reporting Rp1, maka variabel tidak bebasnya akan menjadi menurun sebesar 0,009 dengan anggapan jika variabel tidak terikat lainnya dari model regresi tetap. 


\section{Hipotesis}

Uji Partial (Uji t)

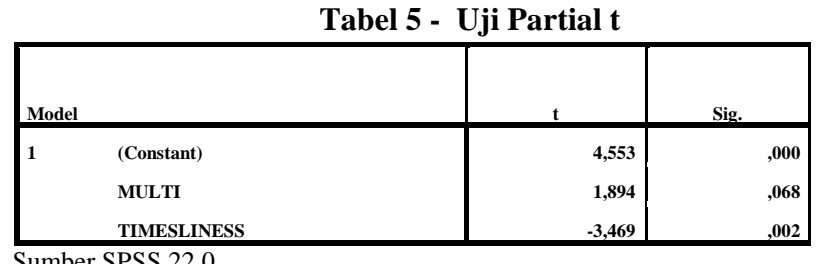

Degree of freedom uji ini senilai 29 dan tingkat regresi 2, maka diperoleh hasil t-tabel adalah 2,04523 sehingga didapatkan hasil sebagai berikut:

1. Nilai t-hitung Multinationality 1,894 <2,04523 dengan sig. 0,068 > $\alpha 0,05$ hal ini menghasilkan Hipotesa0-1 diterima dan Hipotesa H1 ditolak. Disimpulkan bahwa Multinationality tidak berpengaruh terhadap Tax Avoidance.

2. Nilai t-hitung Timeliness of Financial Reporting $-3,469<2,04523$ dengan signifikasi 0,002 lebih kecil dari 0,05 hal ini menghasilkan Hipotesa0-2 ditolak dan Hipotesa $\mathrm{H} 2$ diterima. Disimpulkan bahwa Timeliness of Financial Reporting berpengaruh negatif terhadap Tax Avoidance.

\section{Uji Fisher (Uji F)}

Tabel 6. Uji Fisher (F)

\begin{tabular}{|ll|r|r|c|}
\hline Model & & Df & F & Sig. \\
\hline 1 & Regression & 2 & 6,076 &, $006^{\mathrm{b}}$ \\
& Residual & 29 & & \\
& Total & 31 & & \\
\hline
\end{tabular}

Sumber SPSS 22.0

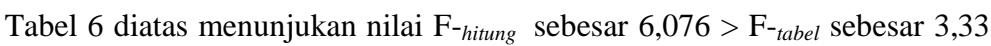
$(\alpha=0,05 ; \mathrm{df}$ regression $=2 ; \mathrm{df}$ residual $=29)$ pada tingkat sig. $0,006<0,05$, maka dikatakan hipotesa H0 tidak diterima dan Hipotesa 3 tidak ditolak yang memiliki arti bahwa hasil uji $\mathrm{F}$ menunjukan bahwa dalam penelitian ini secara simultan adanya pengaruh secara signifikan diantara variabel multinationality (X1) dan timeliness of financial reporting (X2) terhadap effective tax rate (Y)

\section{KESIMPULAN DAN SARAN}

\section{Kesimpulan}

1. Pengujian hipotesis ini dilakukan terhadap variabel Multinationality memperoleh hasil signifikansi senilai 0,068 > 0,05 dengan nilai $\mathrm{t}_{\text {-hitung }}$ senilai 
$1,894<2,04523$ dengan nilai sig. $\alpha=0,05$ dengan nilai degree of fredom (df) 29 yang diperoleh dari nilai $n-k$ yaitu $32-3=29$. Sehingga hasil penelitian ini tidak terdapat pengaruh antara Multinationality terhadap effective tax rate.

2. Variabel timeliness of finacial reporting memperoleh hasil signifikan senilai 0,002 lebih kecil dari 0,05 dengan nilai $t_{\text {-hitung }}$ senilai $-3,469<2,04523$ sdangkan nilai signifikansi $\alpha=0,05$ dua arah dengan nilai degree of fredom (df) 29 yang diperoleh dari nilai (n-k.) yaitu $32-3=29$. Sehingga variabel timeliness of finacial reporting berpengaruh negarif secara signifikan terhadap effective tax rate.

3. Variabel Multinationality, dan variabel timeliness of finacial reporting secara bersama-sama berpengaruh terhadap effective tax rate.

\section{Saran}

1. Perlu adanya jumlah sampel yang lebih banyak lagi pada penelitian selanjutnya agar hasil yang didapatkan bertambah baik.

2. Penelitian selanjutnya perlu menambahkan jangka waktu observasi lebih panjang untuk memperoleh sampel lebih banyak lagi.

3. Data yang digunakan dapat bersumber dari literasi-literasi lain sebagai tambahan bukti pendukung.

4. Menggunakan variabel independent yang baru untyk menambah atau menggantikan variabel independent yang digunakan dalam penelitian ini.

\section{DAFTAR PUSTAKA}

Aryobimo, Putut Tri. (2012). Pengaruh Persepsi Wajib Pajak Tentang Kualitas Pelayanan Fiskus terhadap Kepatuhan Wajib Pajak dengan Kondisi Keuangan Wajib Pajak dan Preferensi Risiko sebagai Variabel Moderating (Studi Empiris terhadap Wajib Pajak Orang Pribadi di Kota Semarang.).

Bawono, Adetya Agung Kusumo. (2015). Pengaruh Ukuran Perusahaan, Leverage, Profitabilitas, Cakupan Operasional Perusahaan, dan Sertifikasi Iso 14001 terhadap Pengukapan Corporate Social Responsibility (Studi pada Perusahaan Manufaktur yang Terdaftar di BEI Tahun 2012-2013.). Skripsi Universitas Diponegoro, Semarang.

Baridwan, Zaki. (2010). Intermediate Accounting. Yogyakarta: Liberty

Bursa Efek Indonesia. Sejarah Perusahaan, Peraturan dan Laporan Keuangan Perusahaan Manufaktur Sektor Industri tahun 2012-2016 diakses tanggal 21/3/2017. 
Edwin, Alexius Verdi Permana. (2012). Analisis Faktor-Faktor yang Mempengaruhi Ketepatan Waktu Penyampaian Laporan Keuangan. Skripsi. Universitas Lampung.

Ghozali, Imam. (2016). Aplikasi Analisis Multivariete dengan Program IBM SPSS 23. Badan Penerbit Universitas Diponegoro. Semarang.

Hidayah, Nurul. (2015). Pengaruh Perusahaan Keluarga, Multinational Company, dan Kepemilikan Institusional Terhadap Tax Avoidance (Studi Pada Perusahaan Manufaktur yang Terdaftar di Bursa Efek Indonesia Periode 2010-2012.) Jom FEKON Vol. 2 N0.2 Oktober 2015. Universitas Riau Pekanbaru.

Nuraini, Novia Suci. (2014). Analisis Faktor-Faktor yang Mempengaruhi Thin Capitalization Pada Perusahaan Multinasional di Indonesia. Skripsi Universitas Diponegoro, Semarang.

Pramana, Aviandika Heru. (2014). Pengaruh Pajak Bonus Plann, Tunneling Incentive, dan Debt Covenant terhadap Keputusan Perusahaan untuk Melakukan Transfer Pricing (Studi Empiris pada Perusahaan Manufaktur yang terdaftar di Bursa Efek Indonesia Tahun 2011-2013. Skripsi Universitas Diponegoro, Semarang.

Prastiwi, Kristantina Wahyu. (2015). Pengaruh Penghindaran Pajak Terhadap Nilai Perusahaan, Transparansi Informasi Sebagai Variabel Pemoderasi. Skripsi Universitas Diponegoro, Semarang.

Resmi, Siti. (2013). Perpajakan Teori dan Kasus. Penerbit Salemba Empat Jakarta.

Setyowati, Rr. Dyah Eko. (2012). Analisis Pengaruh Faktor Kepuasan Kerja Terhadap Komitmen Karyawan pada CV. Cendikia Mandiri. STIE Bisnis Indonesia, Jakarta.

Sugiyono. (2014). Metode Penelitian Kuantitatif Kualitatif dan $R \&$ D. Alfabeta. Bandung. (2016). Metode Penelitian Kuantitatif Kualitatif dan $R \& D$. Alfabeta. 